\section{Wetlands in agricultural landscapes- Significant findings and recent advances from CEAP-Wetlands}

\author{
D.M. Mushet and W.R. Effland
}

\begin{abstract}
The Wetlands Component of the USDA's Conservation Effects Assessment Project (CEAP-Wetlands) is a multi-agency effort advancing science related to quantifying and interpreting effects and effectiveness of conservation practices and programs on ecosystem services provided by wetlands in agricultural landscapes. This special section originated from a symposium held at the 73rd Soil and Water Conservation Society's International Annual Conference in Albuquerque New Mexico, July 29 to August 1, 2018. The symposium was jointly organized by the USDA Natural Resources Conservation Service and the US Geological Survey. To facilitate CEAP-Wetlands efforts, several regional assessments were conducted across the United States. These regional assessments were designed to address science gaps hindering wetland conservation and to develop tools facilitating conservation assessments. Conservation decisions affect not just agricultural wetlands, but also the services that these complex ecosystems provide to society. Papers in this special section of the Journal of Soil and Water Conservation present key findings and recent advances from several CEAP-Wetlands regional assessments and discuss the significant contributions of each assessment to an ever-increasing understanding of wetland ecosystems and their provisioning of ecosystem services. Modeling efforts using the Agricultural Policy and Environmental eXtender (APEX) and other process-based models are an integral component of CEAP-Wetlands. Results of these modeling efforts are also presented, and conservation implications are discussed.
\end{abstract}

Key words: Agricultural Conservation Easement Program-Conservation Effects Assessment Project-conservation practices-Conservation Reserve Program-ecosystem servicesInVEST — wetland assessments-Wetlands Reserve Program

The USDA Conservation Effects
Assessment Project (CEAP) is "a
multi-agency effort to quantify the
environmental effects of conservation
practices and programs and develop
the science base for managing the agri-
cultural landscape for environmental
quality" (USDA NRCS 2019). Voluntary
actions taken by private owners and managers
across the nation, and supported by various
USDA programs, provide for the vast majority
of conservation implemented on agricultural
lands in the United States. These voluntary
actions support the ability of natural ecosys-
tems embedded within agricultural landscapes
to continue to provide a diverse suite of ser-
vices valued by society, i.e., ecosystem services.

The CEAP effort consists of several components including four National Assessments: CEAP-Cropland, CEAP-Grazing Lands, CEAP-Wildlife, and CEAP-Wetlands. The CEAP-Wetlands National Assessment, hereafter referred to simply as CEAP-Wetlands, was initiated in 2003 (Eckles 2011).

The purpose of CEAP-Wetlands is to develop a broad collaborative foundation that facilitates production and delivery of scientific data, results, and information to help make conservation decisions affecting wetland ecosystems and associated services. The effectiveness of USDA conservation practices and farm bill conservation programs is emphasized. CEAP-Wetlands has five interrelated goals to (1) conduct regional collaborative inves- tigations, (2) build science collaborations, (3) document the scientific knowledge base and gaps in knowledge about the effects conservation practices and programs have on wetland ecosystem services, (4) analyze USDA Natural Resources Conservation Service (NRCS) conservation practice and program data to illustrate conservation activities supporting CEAP-Wetlands research and monitoring activities, and (5) develop a national agricultural wetlands monitoring process in collaboration with the National Resources Inventory (NRI) program to promote the conservation of wetlands in agricultural settings.

While maintaining a national vision, CEAP-Wetlands has focused primarily on 11 distinct regions within the United States that contain particularly abundant wetland resources in association with agricultural fields (figure 1). Regional assessments within CEAP-Wetlands have been completed in the Prairie Pothole Region, Central California Valley, the High Plains, Mississippi Alluvial Valley, and the Mid-Atlantic Lower Coastal Plain. Data collection for approximately 1,000 wetland sites across the five regional assessments focused on evaluating the following wetland ecosystem services: floodwater storage, wildlife habitat, biotic conservation and sustainability, erosion prevention and sedimentation, nutrient and pesticide containment (reduction of transport), carbon (C) sequestration, and greenhouse gas emission reduction. This regional approach within the National Assessment is due to the diverse nature of wetland systems across the United States and the region-specific functioning of these complex systems. However, commonalities among regions have emerged that will facilitate modeling and quantifications of conservation effects at the national scale.

This special section of the Journal of Soil and Water Conservation (JSWC) originated from a symposium at the $73^{\text {rd }}$ Soil and Water Conservation Society (SWCS) International Annual Conference held in Albuquerque, New Mexico, from July 29 to August 1, 2018. The symposium was jointly organized by the USDA NRCS and the US Geological Survey. Presentations in the SWCS sympo-

David $M$. Mushet is a research wildlife biologist, US Geological Survey, Northern Prairie Wildlife Research Center, Jamestown, North Dakota. William $\mathbf{R}$. Effland is a retired soil scientist, USDA Natural Resources Conservation Service, Resource Assessment Division, Beltsville, Maryland. 


\section{Figure 1}

Map depicting areas where regional assessments have been conducted under the Conservation Effects and Assessment Project (CEAP) Wetlands National Assessment (CEAP-Wetlands).

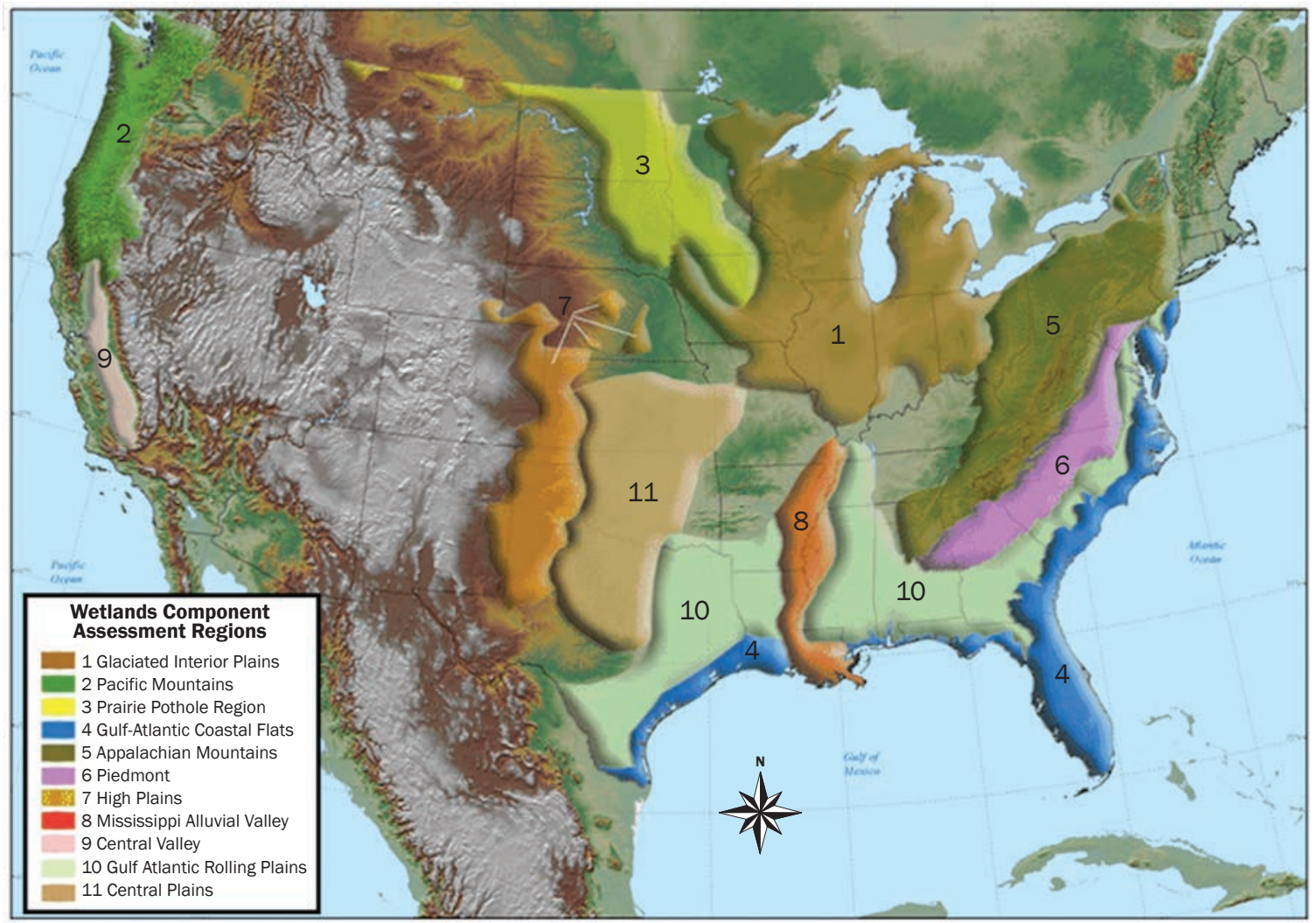

sium provided information on key findings and recent advances from several CEAPWetlands regional assessments and discussed the recent contributions of each assessment to an ever-increasing understanding of wetland ecosystems in agricultural settings and their provisioning of ecosystem services. Modeling efforts are an integral component of all CEAP assessments, including CEAP-Wetlands. Results from several CEAP-Wetlands modeling efforts were also presented in the symposium and conservation implications discussed. As with the symposium, the papers presented in this special section provide recent activities and findings from several of the CEAP-Wetlands regional assessments along with modeling results, advances, and discussions.

Following this introductory text, Lee et al. (2020, XXX-XXX) provide an overview of information learned from the study of 48 current or historical wetland sites in the Mid-Atlantic Lower Coastal Plain as part of the CEAP-Wetlands Mid-Atlantic Regional Assessment. Overall, they found that restoration tended to enhance the biodiversity, biogeochemical, and hydrologic functions of wetlands. However, they also found that not all functions have benefitted equally from past restoration efforts, indicating potential trade-offs between restoration approaches. Findings from the Mid-Atlantic Regional Assessment suggested multiple actions that could be taken to enhance wetland conservation practices. Lee et al. detail eight of these actions in their paper.

Following Lee et al., McKenna et al. (2020, XXX-XXX) provide methodologies that detail how depressional wetlands could be included in National Assessments through use of the Agricultural Policy and Environmental eXtender (APEX) model. Along with the Soil and Water Assessment Tool (SWAT), APEX is the primary process-based model being used by other CEAP National Assessments (i.e., CEAP-Croplands and CEAP-Grazing Lands). McKenna et al. demonstrate how depressional wetlands within agricultural fields can be simulated in APEX and provide direct applicability to assessments underway by other CEAP National Assessments. For example, while CEAP-Croplands does not currently consider the effects of wetland basins embedded in a field on water flows or sediment and nutrient transport, methodology presented by McKenna et al. will allow this missing effect on edge-of-field measures to be incorporated and quantified. In addition to quantification of wetland effects on edge-offield losses, their methodology also allows for measurement of the impact of upland conservation practices, e.g., vegetated buffers, on the functionality of wetland ecosystems and the services they can provide.

In an effort to improve the ability for within-wetland processes to be simulated in models used by CEAP-Wetlands and other CEAP National Assessments (e.g., APEX), Williams et al. $(2020, \mathrm{XXX}-\mathrm{XXX})$ provide information needed to incorporate the growth of wetland plants and wetland-plant functional groups into process models. Williams et al. used field data collected across multiple CEAP-Wetlands regions and performed example simulations of plant growth using the Agricultural Land Management and Numerical Assessment Criteria (ALMANAC) model to demonstrate the utility of the plant-growth parameters they provide for process-based modeling of wetlands. 
Kim et al. (2020, XXX-XXX) provide a case study in which they use the APEX model, calibrated and validated with measured nutrient flows entering and leaving wetlands, to model wetland processes in the Central Valley of California.In their modeling effort, they explore the influence of artificial hydrology on nutrient loads in scenarios representing four wetland water-management regimes commonly used in the Central Valley. Their modeling results suggest that once properly calibrated and validated, the APEX model can effectively quantify wetland-management effects on water balance, water quality, and plant communities in the artificial wetlands of the Central Valley. In their paper, they highlight the linkages between wetland management and water use, and their combined influence on ecosystem-service functions of managed wetlands.

While not published in this JSWC special section, a related CEAP-Wetlands paper, (Mushet and Roth 2020), presents information on use of a geographically based modeling system to quantify ecosystem services provided by wetlands in agricultural landscapes. They describe how through use of a geographic model, ecosystem services that are not well suited for incorporation into process-based models such as APEX can be quantified. They then describe how results from these more habitat-focused geographically based models can be combined with results from process-based models to provide for the identification of tradeoffs among a broader set of ecosystems services. As a demonstration of the value of geographically based modeling, they perform a series of model runs using the geographically based Integrated Valuation of Ecosystem Services and Tradeoffs (InVEST) model to explore the influence of wetland conservation on wildlife habitats, plant communities, floral resources, and $\mathrm{C}$ stores in the Des Moines Lobe ecoregion of the Prairie Pothole Region.

The research papers of this JSWC special section conclude with a paper by Backhaus et al. (2020, XXX-XXX), who examined the feasibility of using readily available, remotely sensed data to perform functional assessments at landscape scales. In their study, they used Watershed-based Preliminary Assessment of Wetland Function methods to assess 15 depressional wetlands in the US Mid-Atlantic Coastal Plain. Sites studied included natural wetlands, restored wetlands, and prior converted croplands, thus spanning a gradient of alteration intensity. Their results indicated that the Watershed-based Preliminary Assessment of Wetland Function methodology can be used to differentiate wetland condition along a gradient of alteration. However, they found that further refinement of the methodology is needed in order to assess functions related to biogeochemistry and water quality.

The special feature also includes an A Section paper by Thompson et al. (2020, $\mathrm{XXX}-\mathrm{XXX}$ ). In their paper, Thompson et al. present a system for the remote classification of wetlands into hydrogeomorphic (HGM) classes that better facilitate wetland ecosystem-service quantifications than systems currently being used, such as the USDA's NRI. In addition to classifying wetlands into HGM classes, Thompson et al rank ecosystem-service models developed for playa wetlands of the High Plains as they demonstrate the utility of taking an HGM approach in wetland evaluations. While the system presented by Thompson et al. is specific to playa wetlands of the High Plains, the concepts and ideas presented are designed to facilitate expanded use for evaluations of wetland ecosystem services at a national scale.

As a whole, the papers in this special section contribute to a greater understanding of the influence of conservation programs and practices on wetland ecosystems in agricultural landscapes. These papers also provide methodologies for modeling and quantifying the ecosystem services wetlands provide in addition to the food and energy services provided by the agricultural landscapes within which they are often embedded. The information provided in this set of papers also increases our knowledge related to how conservation practices implemented outside of the wetland system can influence the sustainability of wetlands in terms of their ability to sustainably provide these ecosystem services. CEAP-Wetlands has a proven history of providing the information needed to manage the nation's agricultural landscapes for environmental quality. The papers provided in this special section demonstrate that as our knowledge base continues to grow, we move ever closer to realizing a national-scale assessment of the influence of conservation programs on wetland ecosystem services.

\section{Acknowledgements}

Funding in support of the multiple research efforts described in this JSWC special section was provided by the USDA Natural Resources Conservation Service's CEAP-Wetlands
National Assessment. We thank Max post van der Burg (research ecologist, US Geological Survey, Jamestown, North Dakota) and two anonymous reviewers for providing their critical reviews of this introduction to the special section.

\section{Disclaimer}

USDA is an equal opportunity provider, employer, and lender. Any use of trade, firm, or product names is for descriptive purposes only and does not imply endorsement by the US Government.

\section{References}

Backhaus, P.J., S. Lee, M. Nassary, G. McCarty, M. Lang, and R.P. Brooks. Evaluating a remote wetland functional assessment along an alteration gradient in coastal plain depressional wetlands. Journal of Soil and Water Conservation doi:10.2489/jswc.2020.00094

Eckles, S.D. 2011. Special Issue: Linking science, policy, and management to conserve wetlands in agricultural landscapes. Ecological Applications 21:S1-S2.

Kim, S., J. Jeonig, S.N. Kahara, S. Kim, and J.R. Kiniry. 2020. APEX simulation: Water quality of Sacramento Valley wetlands impacted by waterfowl droppings. Journal of Soil and Water Conservation doi:10.2489/ jswc. 2020.00117.

Lee, S., G.W. McCarty, M.W. Lang, and X. Li. 2020. Overview of the USDA Mid-Atlantic Regional Wetland Conservation Effects Assessment Project. Journal of Soil and Water Conservation doi:10.2489/jswc.2020.00097.

McKenna, O., D.M. Mushet, K. Behman, J.M. Osorio, and L. Doro. 2020. Development of a novel framework for modeling field-scale conservation effects of depressional wetlands in agricultural landscapes. Journal of Soil and Water Conservation doi:10.2489/jswc.2020.00096.

Mushet, D.M., and C.L. Roth. 2020. Modeling the supporting ecosystem services of depressional wetlands in agricultural landscapes. Wetlands. https://doi. org/10.1007/s13157-020-01297-2.

USDA NRCS (Natural Resources Conservation Service). 2019. Conservation Effects Assessment Project (CEAP). Washington, DC: USDA Natural Resources Conservation Service. https://www.nrcs.usda.gov/wps/ portal/nrcs/main/national/technical/nra/ceap/.

Thompson, A.J., S.T. McMurry, and L.M. Smith. 2020. Depressional wetland classification and ecosystem service predictive models for the Integrative Landscape Modeling partnership. Journal of Soil and Water Conservation 10.2489/jswc.2020.0103A.

Williams, A.S., D.M. Mushet, M. Lang, G.W. McCarty, J.A. Shaffer, S.N. Kahara, M.-V.V. Johnson, and J.R. Kiniry. 2020. Improving our ability to include freshwater wetland plants in process-based models. Journal of Soil and Water Conservation doi:10.2489/jswc.2020.00089. 